\title{
Effect of Sex Hormone-Binding Globulin on Polycystic Ovary Syndrome: Mechanisms, Manifestations, Genetics, and Treatment
}

\author{
Chuan Xing, Jiaqi Zhang, Han Zhao, Bing He \\ The First Department of Endocrine, Shengjing Hospital of China Medical University, Shenyang City, Liaoning Province, People's Republic of China \\ Correspondence: Bing He, Tel +86-18940259707, Email hebing7557@I63.com
}

\begin{abstract}
Polycystic ovary syndrome (PCOS) is one of the most common endocrine diseases causing infertility in women of childbearing age. It is characterized by hyperandrogenemia (HA), chronic anovulation, and polycystic ovary morphology (PCOM). Most women with PCOS have metabolic abnormalities. Sex hormone-binding globulin (SHBG), a transport carrier that binds estrogen and androgens and regulates their biological activity, is usually used as an indicator of hyperandrogenism in women with PCOS. Low serum SHBG levels are considered a biomarker of metabolic abnormalities and are associated with insulin resistance (IR), HA, and abnormal glucose and lipid metabolism in PCOS patients. SHBG is also related to the long-term prognosis of PCOS, whereas SHBG gene polymorphism is associated with PCOS risk. In addition, the administration of metformin (MET), glucagon-like peptide-1 receptor agonists (GLP-1 RAs), thiazolidinediones (TZDs), compound oral contraceptives (COCs), as well as nutrient supplements such as inositol (MI), vitamin D, and synbiotics can regulate SHBG levels to ameliorate PCOS complications and improve prognosis. This review focuses on the interaction between SHBG and various PCOS complications as well as the regulation of SHBG by various drugs and nutrients and its therapeutic effects on PCOS.
\end{abstract}

Keywords: sex hormone-binding globulin, polycystic ovary syndrome, hyperandrogenemia, treatment

\section{Introduction}

Polycystic ovary syndrome (PCOS) is a complex and common reproductive and endocrine disease that affects up to $10 \%$ of women of childbearing age. It is characterized by hyperandrogenemia (HA), chronic anovulation, and polycystic ovary morphology (PCOM). ${ }^{1}$ The 2003 Rotterdam Consensus Symposium of the European Society of Human Reproduction and Embryology and the American Society of Reproductive Medicine (ESHRE/ASRM) proposed the definition of PCOS with at least two of the following three criteria: amenorrhea/oligomenorrhea (AO), clinical or biochemical hyperandrogenism (HA) and polycystic ovary (PCO) ultrasound examination. Thus, PCOS is divided into four phenotypes: (fullblown phenotype: HA + AO + PCOM; non-PCO phenotype:HA + AO; non-hyperandrogenic phenotype: AO + PCOM; ovulatory phenotype: $\mathrm{HA}+\mathrm{PCOM}){ }^{2,3}$ PCOS has complex reproductive and metabolic characteristics; important driving factors such as insulin resistance (IR) and HA affect the metabolism and reproductive capacity of women with PCOS, with approximately $75 \%$ of adult women with PCOS presenting with infertility. ${ }^{4}$ With an unclear etiology and a complicated pathological mechanism, PCOS is believed to be associated with factors such as the hypothalamicpituitary-ovarian axis and adrenal dysfunction, genetics, and metabolism. ${ }^{5}$ In addition, HA is considered a key feature of PCOS. A genome-wide association study (GWAS) carried by Dapas et al revealed 2 distinct PCOS subtypes: the "reproductive" group (21-23\%) which was characterized by higher LH and SHBG levels with relatively low BMI and insulin levels; and the "metabolic" group (37-39\%) which was characterized by higher BMI, glucose, and insulin levels with lower SHBG and LH levels. ${ }^{6}$ Sex hormone-binding globulin (SHBG), a sex hormone transporter, is produced by the liver and binds with circulating sex steroids with a high affinity to regulate the concentration of biologically active sex hormones in the blood, affecting their bioavailability. Therefore, SHBG can be used to assess the severity of 
hyperandrogenism and evaluate treatment efficacy. ${ }^{7}$ The complications and long-term prognosis of PCOS may be related to serum SHBG, which plays an important role in the pathogenesis of PCOS. The concentration of SHBG in PCOS patients is typically low because these women have elevated androgen levels and usually present with compensatory HA and IR. In addition, the synthesis and secretion of SHBG in the liver are inhibited by androgens and insulin. Compared with those in healthy people, testosterone levels in PCOS patients increase significantly. HA is one of the reasons for the low serum SHBG levels. ${ }^{8}$ A meta-analysis revealed that obesity-related metabolic abnormalities in women with PCOS were associated with significantly reduced SHBG levels. ${ }^{9}$ Since adolescents and children are increasingly becoming obese, obesity could affect the development of adolescent girls and increase PCOS risk. Clinical observations have shown that childhood obesity is an initial sign of IR and a precursor of PCOS. The relationship between obesity and PCOS is partly associated with the adverse effects of obesity on the synthesis and secretion of SHBG, which in turn increases the bioavailability of testosterone. Thus, relatively lower serum SHBG levels have been identified as a risk factor for PCOS in adolescents. ${ }^{10}$ Therefore, understanding the role of SHBG in the early development of the syndrome may help clinicians identify PCOS tendencies and intervene early to improve metabolic and reproductive outcomes. ${ }^{11}$ PCOS management strategies include lifestyle changes, such as diet and physical activity, as a first-line treatment; however, these have been reported to have a negligible effect on reducing weight or treating PCOS-related symptoms. ${ }^{12}$ Medications are used as second-line treatments; nevertheless, they have not been openly approved for PCOS treatment because they are primarily used to treat other diseases, such as type 2 diabetes (T2DM). Recently, various new therapeutic drugs for treating T2DM have broadened the range of specific treatment options for PCOS patients. ${ }^{13}$ This review focuses on the interaction between SHBG and various PCOS complications as well as the regulation of SHBG by various drugs and nutrients and its therapeutic effects on PCOS.

\section{The Biochemistry, Expression, and Production of SHBG}

SHBG is a $90-100-\mathrm{kDa}$ homodimeric glycoprotein with two identical peptide chains. ${ }^{14}$ Circulating SHBG is mainly produced by the liver and is regarded as the primary protein that binds and transports testosterone (T), estradiol (E2), and other sex steroids in plasma with high affinity. In addition, SHBG regulates the concentration of biologically active sex hormones in the blood, affecting their bioavailability. ${ }^{15}$ The concentration of free active $\mathrm{T}$ in plasma is greatly affected by SHBG concentration. Because $65 \%$ of $\mathrm{T}$ is bound to SHBG and the rest is bound to albumin, only $1-2 \%$ of $\mathrm{T}$ in circulation is free and active; therefore, women with low SHBG may have normal total T levels, but its bioavailability and free testosterone (FT) levels are elevated. Hence, SHBG can be used to evaluate the effect of treatments and measure HA severity. ${ }^{16}$

A recent genome-wide association study (GWAS) and Mendelian randomization analysis have provided new insights into the regulation and function of human SHBG. ${ }^{17}$ Based on the findings of these analyses, we hypothesize that SHBG is a biomarker of both metabolic disorders and self-exposure. The protein involved in systemic metabolism is the so-called liver factor, implying that hepatocytes are the main site for SHBG synthesis. The SHBG gene is located on chromosome 17p13.1, expressing stimulated hepatocyte nuclear factor $4 \alpha$ (HNF-4 $\alpha$ ), constitutive androstane receptors, and inhibitory peroxisomes. ${ }^{18} \mathrm{HNF}-4 \alpha$ is the most important transcription factor, activating SHBG expression in the liver by binding to the DR1 and DR3 cis-element-binding sites located upstream of the SHBG promoter. ${ }^{5}$ These transcription factors are affected by various hormones and metabolism, nutrition, and inflammatory factors, including thyroid hormone, ${ }^{19}$ adiponectin ${ }^{20}$ and various cytokines, including tumor necrosis factor-alpha (TNF- $\alpha$ ), which downregulates HNF-4 $\alpha$ through nuclear factor- $\mathrm{kB}(\mathrm{NF}-\mathrm{\kappa B}) .{ }^{21}$ In addition, mitogen-activated protein kinase (MAPK)/extracellular signal-regulated kinase 1/2 (MEK1/2) and c-Jun N-terminal kinase MAPK signal, which downregulates HNF-4 $\alpha$ through interleukin $\alpha$ (IL $\alpha)$, also influence the aforementioned transcription factors. ${ }^{22}$ Experimental studies using a human liver cancer cell line (HepG2) have shown that monosaccharides (glucose or fructose), insulin, and androgens negatively affect SHBG expression. ${ }^{23}$ The level of HNF- $4 \alpha$ is negatively correlated with lipogenesis in the liver. The conversion of monosaccharides to palmitate inhibits HNF- $4 \alpha$ expression, subsequently inhibiting SHBG. $^{24}$ In addition, SHBG can downregulate de novo lipogenesis, thereby reducing intrahepatic lipid levels. ${ }^{25}$ Moreover, hyperinsulinemia can inhibit HNF-4 $\alpha$ expression and reduce the synthesis and production of SHBG in the liver. $^{26}$ 


\section{Roles of SHBG Levels in Women with PCOS SHBG Levels and Obesity in Women with PCOS}

Obesity is considered one of the most crucial factors leading to the development of PCOS. Obesity aggravates the metabolic phenotype of PCOS, and the incidence of PCOS is higher in overweight and obese patients. ${ }^{27}$ Low plasma SHBG levels have been shown to be related to obesity, especially abdominal obesity. Studies have shown that body weight, particularly the relative amount of adipose tissue and lean muscle, is among the most important determinants of plasma SHBG levels. ${ }^{28}$ Compared with normal-weight PCOS women, obese PCOS women have lower SHBG and higher FT, free androgen index (FAI), insulin resistance homeostasis assessment (HOMA-IR), fasting insulin (FINS), and fasting blood glucose (FG) levels, ${ }^{27}$ indicating that obesity may be an important cause of IR and HA in PCOS women. However, low serum SHBG levels may lead to an increase in T and IR, which has been observed in obese adolescent girls compared with that in girls of normal weight. ${ }^{29}$ Body mass index (BMI) is considered to be negatively correlated with SHBG plasma concentration. A high BMI directly increases the degree of IR in PCOS patients. ${ }^{30}$ Recent evidence confirms that obese women with PCOS have higher IR and lower insulin sensitivity. ${ }^{31}$ Insulin reduces circulating SHBG levels by inhibiting the synthesis of SHBG in the liver, ${ }^{27,32}$ thereby increasing the level of biologically active FT. This elevated serum FT further reduces the insulin clearance rate and aggravates IR, ultimately creating a vicious circle. Hyperinsulinemia caused by obesity can also directly stimulate the ovaries and adrenal glands of women with PCOS to produce excessive androgens. ${ }^{32}$

\section{SHBG Levels and Hyperandrogenemia in Women with PCOS}

HA is a major feature of PCOS and a significant cause of infertility in women with PCOS. In these women, excessive androgens are mainly produced by the ovaries and adrenal glands, inhibiting the selective growth of follicles, leading to increased follicular atresia, and ultimately causing ovulation disorders, which are the direct cause of anovulation in patients with HA and PCOS. ${ }^{33}$ Androgen levels are also positively correlated with IR in PCOS patients because HA induces IR by reducing insulin clearance and increasing lipoprotein lipase activity and triacylglycerol release. Compensated hyperinsulinemia, in turn, further aggravates HA. ${ }^{34}$ A meta-analysis of 16 independent studies showed that young women with PCOS, especially obese adolescents, have reduced serum SHBG levels. ${ }^{35}$ SHBG reduces HA and IR by binding free androgens, thereby reducing FT levels. Compared with that in healthy individuals, the T level in PCOS patients is significantly higher, and SHBG levels are negatively correlated with T levels. ${ }^{36}$ Studies have shown that $\mathrm{T}$ in HepG2 cells inhibits SHBG production, ${ }^{37}$ and at the same time, even at low doses, exogenous androgens can also inhibit SHBG. ${ }^{38}$ Therefore, it can be concluded that HA is one of the reasons for the low serum SHBG level in PCOS patients. In any case, since the human SHBG promoter does not contain androgen binding elements, the androgen signaling pathway may affect SHBG expression by regulating other factors. ${ }^{39}$ Unlike the effect of T on SHBG, E2 increases the level of SHBG in the liver, which may be due to the upregulation of HNF- $4 \alpha$ gene expression mediated by estrogen receptor- $\alpha(\mathrm{ER}-\alpha){ }^{36}$

\section{SHBG Levels and Hyperinsulinemia in Women with PCOS}

Approximately $75 \%$ of PCOS patients show IR, a prominent PCOS feature. ${ }^{30}$ IR is a condition where the response of cells to a given environmental insulin concentration is lower than that of normal controls, ${ }^{40}$ varying with tissue type. Hepatic IR is aggravated by the upregulation of several genes in de novo lipogenesis (DNL). DNL is stimulated by sterol regulatory element-binding protein 1c (SREBP-1c), which enhances the transcription of several lipogenic enzymes, especially adenosine triphosphate citrate lyase (ACL), acetyl-CoA carboxylase (ACC), fatty acid synthase (FAS), and stearoyl-CoA desaturase (SCD). ${ }^{41}$ IR and the resulting hyperinsulinemia are considered to be the underlying cause of the relationship between metabolic disorders and reproductive dysfunction in PCOS. According to observations, insulin affects SHBG, and hyperinsulinemia prevents SHBG secretion and synthesis, as is the case in healthy individuals. In contrast, patients with hyperinsulinemia have significantly lower serum SHBG levels. ${ }^{42}$ Using unsupervised phenotypic cluster analysis from GWAS data, two different PCOS subtypes have been identified: a "reproductive" group with high SHBG levels and low BMI and insulin levels and a "metabolic" group with prominent BMI, high glucose and insulin 
levels, and low SHBG levels. This finding emphasizes that PCOS is a heterogeneous reproductive disease with different underlying biological mechanisms. The metabolic phenotype (non-reproductive group) with IR and low SHBG levels is a high-risk population for infertility. ${ }^{6}$ Clinical studies in adolescent girls have shown that SHBG is a strong predictor of insulin sensitivity, and a decline in SHBG is indicative of IR development. ${ }^{43}$ Therefore, understanding the correlation between SHBG and IR is essential to explain the cause of PCOS and to treat PCOS complications. At present, insulin is considered to be an important regulator of SHBG metabolism. When insulin sensitivity decreases and insulin compensatory secretion increases, thereby downregulating SHBG gene transcription and SHBG production. ${ }^{44}$ An in vivo animal study using SHBG transgenic mice and wild-type mice revealed that SHBG overexpression can prevent a high-fat diet (HFD) from inducing obesity and insulin resistance and also eliminate the increase in insulin, leptin, and resistin levels as well as the decrease in adiponectin levels induced by a HFD. ${ }^{45}$ Triglycerides accumulate in the liver, and IR is negatively correlated with SHBG mRNA, HNF-4 $\alpha$ mRNA, and circulating SHBG levels. In addition, these mRNA and serum SHBG levels are negatively correlated with liver triglyceride content and ACC activity. ${ }^{46}$ This may explain the molecular mechanism by which hyperinsulinemia downregulates HNF-4 $\alpha$ expression, thereby reducing SHBG production in the liver by upregulating ACC lipogenesis. PPAR- $\gamma$ competes with HNF- $4 \alpha$ for the DR3 binding site of the SHBG promoter. Therefore, PPAR- $\gamma$ can be used as an inhibitor of SHBG expression to increase SHBG production by reducing PPAR- $\gamma$ activity ${ }^{47}$ Although the mechanism by which SHBG affects IR is unclear, in vitro studies using human IR cell models have shown that the decreased expression and mRNA of SHBG protein, IRS-1, IRS-2, PI3Kp85a, GLUT-3, and GLUT-4 imply that SHBG expression may be downregulated to participate in developing local and systemic IR through the PI3K/ AKT pathway. ${ }^{48}$

\section{SHBG Levels and Ovarian Dysfunction in Women with PCOS}

In adolescents with PCOS, low SHBG levels are usually associated with fatty liver disease and hyperinsulinemia, which may reflect a new liver-ovarian axis. ${ }^{49}$ At the initial stage of PCOS in non-alcoholic fatty liver disease (NAFLD) patients, the decrease in SHBG synthesis in the liver leads to an increase in androgen bioavailability. However, the continued increase in free androgens in the bloodstream eventually leads to ovarian dysfunction and excessive androgen secretion. The mechanism underlying liver and ovarian HA may involve the disruption of the negative feedback regulation of the hypothalamic-pituitary-ovarian axis. ${ }^{49}$ Low SHBG levels result in a sustained increase in the circulating free androgen concentration, which reduces hypothalamic sensitivity to luteinizing hormone (LH) pulses, leading to the excessive release of gonadotropin-releasing hormone $(\mathrm{GnRH})$, which in turn stimulates the pituitary to release LH. Adolescents with mild PCOS show increased GnRH and LH pulse frequency and amplitude as well as an increase in the ratio of LH to FSH (>3:1). This increase is exaggerated in adolescent women prone to PCOS, further enlarging their ovaries and increasing androgen production by theca cells, leading to ovarian HA. ${ }^{50}$ Thus, decreased SHBG levels in the liver in NAFLD patients may trigger a cascade of excessive androgen production in adolescents, leading to PCOS development. In addition, NAFLD liver dysfunction may affect sex steroid metabolism, thereby aggravating HA. It can be speculated that increased liver adipogenesis may inhibit liver SHBG synthesis, leading to relative and absolute HA and ovarian dysfunction in PCOS. ${ }^{11}$ On the contrary, low-carbohydrate diets, insulin sensitizers, and phytoestrogens can increase SHBG production by reducing liver fat production and ameliorating fatty liver so as to prevent the progression of ovarian pathology and restore reproductive function. ${ }^{51-53}$

\section{SHBG Levels and Lipid Metabolism Disorders in Women with PCOS}

PCOS with lipid metabolism disorders has been attracting increasing attention. PCOS patient dyslipidemia is mainly characterized by elevated levels of low-density lipoprotein (LDL) and triglycerides (TG) and low levels of high-density lipoprotein (HDL). ${ }^{5}$ Obesity and metabolic syndrome are associated with adipocyte IR, which weakens the inhibition of lipolysis, leading to ectopic lipid deposition in non-fat tissues and the resulting "lipotoxicity." 54 IR in adipose tissue increases lipolysis, leads to the release of non-esterified fatty acids (NEFAs) and lipid intermediates for mobilization to the liver, promotes gluconeogenesis and adipogenesis, and reduces SHBG production. In contrast, low SHBG levels can promote lipid disorders in PCOS patients. ${ }^{5}$ Adipose tissue is an important endocrine tissue that can secrete various active adipokines and inflammatory factors, including leptin, adiponectin, resistin, visfatin, TNF- $\alpha$, C-reactive protein (CRP), 
interleukin-1 (IL-1), and interleukin-6 (IL-6), which may cause local inflammation and exacerbate IR. ${ }^{55}$ Circulating levels of CRP, TNF- $\alpha$, IL-1, and IL-6 in PCOS patients are elevated, ${ }^{56}$ and serum SHBG level is reduced, indicating that these inflammatory cytokines may regulate SHBG expression. The mechanism by which adiponectin reduces liver lipid content involves reducing the level of HNF- $4 \alpha$ and ultimately SHBG production in the liver through AMPK pathway activation. ${ }^{20}$ In patients with obesity and metabolic syndrome, lower SHBG levels are associated with lower adiponectin levels, which may be caused by increased liver adipogenesis, leading to HNF- $4 \alpha$ downregulation. ${ }^{20,56} \mathrm{TNF}-\alpha$ released from fat in the liver can impair hepatic insulin signaling and promote the accumulation of triglycerides in the liver, leading to the inhibition of HNF- $4 \alpha$ mRNA via NF- $\mathrm{kB} .{ }^{57,58}$ In addition, the lipoinflammatory cytokine interleukin- $1 \beta$ $\left(\mathrm{IL}-1 \beta\right.$ ) can inhibit HNF-4 $\alpha$ expression by activating the MEKK-1/2 and JNK/MAPK pathways. ${ }^{22}$ Therefore, adipose tissue IR associated with cell inflammatory factors negatively affects SHBG production in the liver and accelerates metabolism and reproductive disorders. In contrast, in vitro studies using adipocytes and macrophages have shown that SHBG inhibits inflammation and lipid accumulation in macrophages and adipocytes, which may be a potential mechanism underlying the protective effects of SHBG in reducing the incidence of metabolic syndrome and its complications. ${ }^{59}$

\section{SHBG Gene Polymorphism and PCOS}

SHBG is mainly synthesized in the liver and binds androgens and estrogen with high affinity, thereby reducing circulating steroid hormones and making them biologically unavailable for target tissues. Several polymorphisms in the SHBG gene located on chromosome 17 have been shown to alter the liver biosynthesis, plasma levels, and plasma clearance efficiency of SHBG, effectively regulating sex steroid hormone distribution. ${ }^{60}$ The correlation between SHBG gene polymorphisms and serum SHBG levels is of increasing interest for research, while SHBG polymorphisms are considered an important predictor of HA in PCOS women. ${ }^{61}$ The (TAAAA)n motif exists in the upstream region of the SHBG promoter, and it has been confirmed that HA is positively correlated with the (TAAAA)n polymorphism of the SHBG gene promoter. ${ }^{61}$ The $^{2}$ (TAAAA)n pentanucleotide repeat sequence affects the level of SHBG; the shorter the repeat sequence length, the higher the gene transcription. ${ }^{62}$ Variations in the SHBG gene are also associated with metabolic syndrome in obese women and women with PCOS, suggesting that the SHBG gene may be a risk factor for PCOS. ${ }^{63,64}$ In addition, there is a negative correlation between the combined short androgen receptor (AR) CAG repeats and SHBG serum levels. ${ }^{65}$ PCOS women with long SHBG alleles and short CYP19 alleles showed low SHBG and high T, FAI, dehydroepiandrosterone sulfate (DHEAS), and an increased T/E2 ratio. ${ }^{10}$ SHBG metabolism is affected by a functional missense polymorphism in exon 8 , which causes the amino acid to change from aspartic acid to asparagine, thereby increasing the half-life of SHBG. ${ }^{66}$ In contrast, another missense polymorphism, E326K, reduces SHBG levels in women with PCOS but does not affect the BMI, androgens, and insulin-related traits. ${ }^{67} \mathrm{~A}$ meta-analysis concluded that there is no association between the (TAAAA)n repeat polymorphism and PCOS risk, ${ }^{62}$ while other previous studies have shown that SHBG metabolism is markedly dependent on rs1799941 and rs727428 in the SHBG gene without affecting PCOS risk. ${ }^{64,68}$ In addition, a recent study revealed that haplotypes spanning six polymorphisms are associated with increased or decreased susceptibility to PCOS. ${ }^{69}$ A population-based cohort study by Ruth et al reported on a large-scale GWAS on serum SHBG, T, and FT and identified 658 genetic variants that cause changes in serum SHBG levels, including glucokinase regulatory protein (GKRP) coding gene (GCKR; rs1260326), glucokinase gene (GCK; rs1799831), carbohydrate response element-binding protein (ChREBP) coding gene (MLXIPL; rs17145750), and protein 3 gene (PNPLA3; Rs738409), indicating that DNL, rather than intrahepatic lipids themselves, drives the reduction in SHBG levels. ${ }^{17}$ In any case, there is no consistent conclusion as to whether SHBG polymorphism is related to PCOS incidence. These controversies may be due to ethnic differences between the study groups or different PCOS phenotypes (such as BMI and IR). In general, research on PCOS-susceptibility genes is still exploratory; further studies are expected to provide a deeper understanding of the mechanism underlying PCOS.

\section{Therapeutic Agents for Managing SHBG Levels in Women with PCOS}

To assess the impact of various interventions on changes of SHBG levels in women with PCOS, we conducted a computerized literature search using PubMed. Finally, 7 randomized controlled trials (RCTs) and 10 meta-analysis were included from inception to 2021. Their main features are reported in Tables 1 and 2. 
Table I Characteristics of the Included RCTs of Intervention on Changes of Serum SHBG

\begin{tabular}{|c|c|c|c|c|c|}
\hline Study ID & Population & No of Cases & Intervention & Duration & Changes of Serum SHBG \\
\hline Lass et $\mathrm{al}^{70}$ & Obese PCOS (NICHD) & 59 & LS & 52weeks & $8 \mathrm{ng} / \mathrm{mL}$ \\
\hline Hoeger et $\mathrm{al}^{71}$ & Obese adolescent PCOS & 8 & LS & 24weeks & $17.6 \mathrm{nmol} / \mathrm{I}$ \\
\hline Hoeger et $\mathrm{al}^{71}$ & Obese adolescent PCOS & 6 & MET & 24 weeks & $2.5 \mathrm{nmol} / /$ \\
\hline Hoeger et $\mathrm{al}^{71}$ & Obese adolescent PCOS & 10 & COC (EE+DRSP) & 24weeks & $77.1 \mathrm{nmol} / /$ \\
\hline Hoeger et $\mathrm{al}^{71}$ & Obese adolescent PCOS & 10 & PLA & 24weeks & $2 \mathrm{nmol} / \mathrm{l}$ \\
\hline Frøssing et $\mathrm{al}^{89}$ & Overweight PCOS (Rotterdam) & 44 & LIA & 26weeks & $7.4 \mathrm{nmol} / \mathrm{l}$ \\
\hline Frøssing et $\mathrm{al}^{89}$ & Overweight PCOS (Rotterdam) & 21 & PLA & 26weeks & $2 \mathrm{nmol} / \mathrm{l}$ \\
\hline Nylander et $\mathrm{al}^{90}$ & Overweight PCOS (Rotterdam) & 44 & LIA & 26weeks & $7.4 \mathrm{nmol} / \mathrm{l}$ \\
\hline Nylander et $\mathrm{al}^{90}$ & Overweight PCOS (Rotterdam) & 21 & PLA & 26weeks & $2 \mathrm{nmol} / \mathrm{l}$ \\
\hline Morgante et al ${ }^{101}$ & PCOS (Rotterdam) & 20 & $\mathrm{EE}+\mathrm{DRSP}$ & 12 weeks & $61.5 \mathrm{nmol} / /$ \\
\hline Morgante et al ${ }^{101}$ & PCOS (Rotterdam) & 20 & $\mathrm{EE}+\mathrm{CMA}$ & 12 weeks & $56.05 \mathrm{nmol} / \mathrm{l}$ \\
\hline Morgante et al ${ }^{101}$ & PCOS (Rotterdam) & 20 & $\mathrm{EE}+\mathrm{DNG}$ & 12 weeks & $60.7 \mathrm{nmol} / /$ \\
\hline Jamilian et $\mathrm{al}^{121}$ & PCOS (Rotterdam) & 30 & High-dose VitD +MET & 12 weeks & $19.1 \mathrm{nmol} / \mathrm{l}$ \\
\hline Jamilian et al ${ }^{121}$ & PCOS (Rotterdam) & 30 & Low-dose VitD +MET & I2weeks & $4.5 \mathrm{nmol} / /$ \\
\hline Jamilian et $\mathrm{al}^{121}$ & PCOS (Rotterdam) & 30 & MET & I2weeks & $0.7 \mathrm{nmol} / / \mathrm{l}$ \\
\hline Nasri et al ${ }^{126}$ & PCOS (Rotterdam) & 30 & SYN & 12 weeks & $0.5 \mathrm{nmol} / \mathrm{l}$ \\
\hline Nasri et al ${ }^{126}$ & PCOS (Rotterdam) & 30 & PLA & I2weeks & $19.8 \mathrm{nmol} / /$ \\
\hline
\end{tabular}

Abbreviations: CMA, chlormadinone acetate; COC, combined oral contraceptives; DNG, dienogest; DRSP, drosperinone; EE, ethinyl estradiol; LS, lifestyle; MET, metformin; NICHD, National Institute of Child Health and Human Development; PCOS, polycystic ovary syndrome; PLA, placebo; RCT, randomized controlled trial; SHBG, sex hormone-binding globulin; SYN, synbiotic; VitD, vitamin D.

\section{Lifestyle Intervention}

Lifestyle intervention is considered to be the first choice for PCOS, and weight loss in obese women with PCOS is associated with a decrease of androgens and normalization of menstrual cycles. ${ }^{70}$ Hoeger et al found that lifestyle modification alone resulted in a 59\% reduction in free androgen index with a $122 \%$ increase in SHBG in obese adolescents with PCOS. ${ }^{71}$ At the same time, Lass et al confirmed that in contrast to the 33 girls without weight loss, the 26 girls reducing their BMI during the lifestyle intervention (by a mean of $-3.9 \mathrm{~kg} / \mathrm{m} 2$ ) showed lower testosterone levels (by a mean of $-0.3 \mathrm{nmol} /$ liter) and higher SHBG levels (by a mean of $+8 \mathrm{ng} / \mathrm{mL}$ ). The changes in insulin levels in the 1-yr follow-up were significantly correlated to changes in testosterone $(\mathrm{r}=0.38 ; \mathrm{P}=0.002)$ and SHBG $(\mathrm{r}=-0.35$; $\mathrm{P}=0.048$ ) levels. ${ }^{70}$ Moreover, the meta proposed by Haqq et al suggested that lifestyle (diet and exercise) intervention improved the levels of FSH, SHBG, total testosterone, androstenedione, FAI, and FG score in women with PCOS ${ }^{72}$ while Lim et al demonstrated that no significant associations were observed between shift work, exercise or sleep duration, and the androgenic ovarian measures that define PCOS. ${ }^{73}$

\section{Metformin}

Metformin (MET) is a biguanide insulin sensitizer that does not affect insulin secretion but can improve insulin action. Its mechanism of action is to reduce liver glucose production, stimulate the liver and skeletal muscle to carry out insulinmediated glucose uptake, and reduce the utilization of gluconeogenic substrates. ${ }^{74}$ Obese women with PCOS show metabolic characteristics similar to those of T2DM in terms of IR and hyperinsulinemia; therefore, MET has been used as an insulin sensitizer to treat PCOS. ${ }^{75}$ Studies have shown that in addition to regulating ovarian function and restoring a normal menstrual cycle and ovulation, MET also has metabolic and reproductive benefits, including weight loss and inducing relatively lower IR and androgen levels. ${ }^{76}$ Heidari et al concluded that MET could improve endothelial function and ameliorate endothelial dysfunction in women with PCOS, but it has a limited effect in improving glucose metabolism and dyslipidemia. ${ }^{77}$ Guan et al found that overweight women with PCOS treated with MET had significantly improved sex hormone indicators, including T, follicle-stimulating hormone (FSH), and LH; however, MET had no significant regulatory effect on SHBG and androstenedione (A4). ${ }^{78}$ Nonetheless, MET use may be limited by significant side effects such as nausea, vomiting, and gastrointestinal discomfort. The observed poor compliance has prompted clinicians worldwide to find new ways to treat PCOS. ${ }^{79}$ 
Table 2 Characteristics of the Included Meta-Analysis of Intervention on Changes of Serum SHBG

\begin{tabular}{|c|c|c|c|c|c|}
\hline Study ID & Population & $\begin{array}{l}\text { No of } \\
\text { Cases }\end{array}$ & Intervention & Duration & $\begin{array}{c}\text { Changes of Serum } \\
\text { SHBG }\end{array}$ \\
\hline Haqq et $\mathrm{al}^{72}$ & PCOS & $104 / 102$ & LS vs UC & $\begin{array}{c}12- \\
48 \text { weeks }\end{array}$ & $2.37(\mathrm{I} .27,3.47) \mathrm{nmol} / \mathrm{l}$ \\
\hline Guan et al ${ }^{78}$ & Overweight PCOS & $|44 /| 5 \mid$ & UC+PLA/LS vs MET & 6-48weeks & $2.21(-0.20,4.63) \mathrm{nmol} / \mathrm{l}$ \\
\hline Xing et $\mathrm{al}^{91}$ & $\begin{array}{l}\text { Overweight PCOS (Rotterdam/ } \\
\qquad \text { NIH) }\end{array}$ & $77 / 82$ & GLP-IRA vs MET & $\begin{array}{c}12- \\
24 \text { weeks }\end{array}$ & $\mathrm{I} .42(-1.76,4.60) \mathrm{nmol} / \mathrm{I}$ \\
\hline Xing et $\mathrm{al}^{9 !}$ & $\begin{array}{l}\text { Overweight PCOS (Rotterdam/ } \\
\text { NIH) }\end{array}$ & $50 / 82$ & MET + GLP-IRA vs MET & $\begin{array}{c}12- \\
24 \text { weeks }\end{array}$ & $9.22(5.46,12.98) \mathrm{nmol} / \mathrm{l}$ \\
\hline Xing et $\mathrm{al}^{91}$ & $\begin{array}{l}\text { Overweight PCOS (Rotterdam/ } \\
\qquad \text { NIH) }\end{array}$ & $40 / 82$ & MET + TZD vs MET & $\begin{array}{c}12- \\
24 \text { weeks }\end{array}$ & $4.30(0.78,7.82) \mathrm{nmol} / \mathrm{l}$ \\
\hline Xing et $\mathrm{al}^{91}$ & $\begin{array}{l}\text { Overweight PCOS (Rotterdam/ } \\
\text { NIH) }\end{array}$ & $50 / 77$ & $\begin{array}{c}\text { MET + GLP-IRA vs GLP- } \\
\text { IRA }\end{array}$ & $\begin{array}{c}12- \\
24 \text { weeks }\end{array}$ & $7.80(4.75,10.85) \mathrm{nmol} / \mathrm{l}$ \\
\hline Xu et $\mathrm{a}^{97}$ & PCOS (ESHRE/ASRM) & $319 / 324$ & TZD vs.MET & 6-24weeks & $2.28(-0.50,5.06) \mathrm{nmol} / \mathrm{l}$ \\
\hline Unfer et al ${ }^{103}$ & PCOS & $292 / 249$ & MI vs PLA or COC & $\begin{array}{c}12- \\
24 \text { weeks }\end{array}$ & $0.17(-0.25,0.58) \mathrm{nmol} / \mathrm{I}$ \\
\hline $\begin{array}{l}\text { Facchinetti } \\
\text { et al }\end{array}$ & PCOS (Rotterdam) & $37 / 37$ & MET vs MI & 24weeks & $0.04(-0.4 \mathrm{I}, 0.50) \mathrm{nmol} / \mathrm{l}$ \\
\hline Zhang et $\mathrm{al}^{106}$ & $\begin{array}{c}\text { PCOS (NICHD/ESHRE/ASRM/ } \\
\text { AES) }\end{array}$ & $108 / 233$ & IN vs PLA & 8-24weeks & $0.42(0.20,0.63) \mathrm{nmol} / \mathrm{l}$ \\
\hline Zhang et al ${ }^{106}$ & $\begin{array}{c}\text { PCOS (NICHD/ESHRE/ASRM/ } \\
\text { AES) }\end{array}$ & $108 / 139$ & IN vs VitD & 8-24weeks & $0.36(0.07,0.65) \mathrm{nmol} / \mathrm{l}$ \\
\hline Guo et al ${ }^{119}$ & PCOS (NICHD/Rotterdam) & $114 / 100$ & VitD vs PLA & $8-12$ weeks & $0.37[-0.39,1.13] \mathrm{nmol} / \mathrm{l}$ \\
\hline Yazdi et al ${ }^{120}$ & PCOS (NICHD/Rotterdam) & 75 & VitD (before vs after) & 3-12weeks & $0.00(-0.22,0.22) \mathrm{nmol} / \mathrm{l}$ \\
\hline Shamasbi et al ${ }^{127}$ & PCOS & $30 / 30$ & SYN vs PLA & I2weeks & $0.49[-0.02,1.01] \mathrm{ug} / \mathrm{mL}$ \\
\hline Shamasbi et al ${ }^{127}$ & PCOS & $60 / 60$ & PRO vs PLA & I 2weeks & $0.59[0.23,0.96] \mathrm{ug} / \mathrm{mL}$ \\
\hline Shamasbi et al ${ }^{127}$ & PCOS & $90 / 90$ & SYN + PRO vs PLA & I2weeks & $0.56[0.26,0.86] \mathrm{ug} / \mathrm{mL}$ \\
\hline
\end{tabular}

Abbreviations: AES, Androgen Excess Society; COC, combined oral contraceptives; ESHRE/ASRM, European Society for Human Reproduction and Embryology/American Society for Reproductive Medicine; GLP-IRA, glucagon-like peptide-I receptor agonists; IN, inositol; LS, lifestyle; MET, metformin; MI, myo-inositol; NICHD, National Institute of Child Health and Human Development; PCOS, polycystic ovary syndrome; PLA, placebo; PRO, probiotics; SHBG, sex hormone-binding globulin; SYN, synbiotic; TZD, thiazolidinedione; UC, usual care; VitD, vitamin D.

\section{Glucagon-Like Peptide-I Receptor Agonists (GLP-I RAs)}

Incretin is a hormone secreted by the intestine that includes glucose-dependent insulinotropic peptide (GIP) and glucagon-like peptide-1 (GLP-1), both of which are secreted after eating and enhance glucose-stimulated insulin secretion. ${ }^{80}$ The incretin hormone also maintains glucose homeostasis by reducing hepatic glucagon release, slowing gastric emptying, and suppressing appetite, thus helping to control weight and improve glucose metabolism. ${ }^{81}$ The halflife of endogenous GLP-1 is relatively short at only 1-2 minutes, and it is degraded faster by the proteolytic enzyme dipeptidyl peptidase-4 (DPP-4) than GIP, whose half-life is 5 minutes. ${ }^{82}$ Most PCOS studies have found that the secretion and activity of incretin in overweight/obese individuals are impaired. ${ }^{83}$ According to the international evidence-based guideline for the assessment and management of PCOS, incretin therapy (including GLP-1RA and DPP-4 inhibitor) is the latest example of PCOS treatment. ${ }^{13}$ DPP-4 inhibitors are a class of oral anti-diabetic drugs that improve blood sugar control by increasing the endogenous physiological levels of GLP-1 and GIP, whereas GLP-1RA mimics the effects of natural GLP-1 to achieve pharmacological levels DPP-4 inhibitors are resistant to degradation by the DPP-4 enzyme. ${ }^{84}$ Studies have shown that DPP-4 inhibitors and GLP-1RA are effective agents for treating PCOS and preventing its metabolic consequences. ${ }^{85}$

Compared with the hypothalamus, the pituitary has lower GLP-1 mRNA expression, and GLP-1 increases LH release by releasing GnRH. ${ }^{86}$ Acute intracerebral injection of GLP-1 promotes an immediate increase in LH levels before ovulation and significantly increases estrogen and progesterone levels as well as the number of mature follicles. ${ }^{87}$ GLP1RA is also expressed in the ovaries, and it significantly suppresses progesterone levels without affecting estrogen 
synthesis. ${ }^{88}$ Compared with placebo, 26 weeks of liraglutide (a GLP-1 receptor agonist) treatment has brought good weight loss and liver fat reduction effects to women with PCOS. In addition, it could also improve ovulation and HA, including (increasing SHBG levels while reducing FT levels).The increase in SHBG levels in PCOS women after liraglutide treatment may be caused by a combination of weight loss, improvement in IR and HA. ${ }^{89,90}$ Our previous meta-analysis confirmed that for overweight women with PCOS, MET combined with GLP-1 RAs appears to be superior to MET in ameliorating hyperandrogenemia, especially by increasing SHBG. ${ }^{91}$ At the same time, animal experiments by $\mathrm{Wu}$ et al confirmed that rat serum androgen levels were significantly reduced and SHBG content was significantly increased in the groups treated with three different doses of dulaglutide compared with that in the PCOS group induced by DHEA. ${ }^{92}$ In addition, in our previous animal experiments, we found that both MET and exenatide can alleviate glucose and lipid metabolism disorders and hyperandrogenemia and increase the serum SHBG level in a PCOS rat model induced by letrozole combined with an HFD. Interestingly, our results also emphasized that compared with MET, exenatide can have stronger effects on regulating the PI3K/AKT pathway, reducing liver TG deposition, and upregulating the expression levels of SHBG and HNF-4 $\alpha$ in the liver tissue of PCOS-with-IR rats. ${ }^{93}$ Although GLP-1RA and DPP-4 inhibitors have promising therapeutic effects, more extensive clinical trials are needed to determine the role and mechanism of action of incretin-based therapies in improving SHBG levels and managing PCOS.

\section{Thiazolidinediones (TZDs)}

Thiazolidinediones (TZDs) are highly selective synthetic PPAR- $\gamma$ agonists. The pathogenesis of PCOS may be related to changes in the PPAR- $\gamma$ gene. PPAR- $\gamma$ seems to play a key role in fertility and metabolism through its different subtypes, such as PPAR- $\gamma 1$, which can specifically regulate ovarian function. ${ }^{94}$ IR is an important aspect of PCOS, not only observed in obese patients but also in lean women with PCOS, and seems to be an inherent part of the syndrome. ${ }^{95}$ PPAR- $\gamma$ agonists can indirectly improve peripheral IR to reduce androgen synthesis in the ovary, which provides a theoretical and practical basis for TZD therapy to treat PCOS. ${ }^{96}$ A meta-analysis by Xu et al showed that pioglitazone is better than MET in improving the menstrual cycle and ovulation in PCOS patients, whereas MET is better than pioglitazone in improving BMI and FG scores in the treatment of PCOS patients. Nevertheless, there is no significant difference between the two drugs in improving HA and SHBG. ${ }^{97}$ In addition, our previous meta-analysis confirmed that compared with MET only, MET combined with TZDs is superior in menstrual recovery and is more effective in increasing SHBG levels. ${ }^{91}$ However, in the future, large-scale clinical trials are still needed to verify the clinical efficacy and safety of TZDs in the treatment of PCOS.

\section{Combined Oral Contraceptives (COCs)}

For many years, combined oral contraceptives (COCs) have been used as a first-line treatment to ameliorate HA and regulate the menstrual cycle in women with $\mathrm{PCOS} .{ }^{98} \mathrm{COCs}$ are designed to inhibit ovulation by inhibiting the secretion of GnRH and pituitary gonadotropin, thus inhibiting the secretion of LH in PCOS patients. On the one hand, the estrogen component of COCs increases SHBG circulating levels, thereby reducing serum FT concentration. On the other hand, the progesterone component of COCs inhibits LH secretion, resulting in decreased ovarian androgen production. In addition, the anti-androgen progesterone inhibits 5- $\alpha$ reductase activity, thereby reducing the conversion of $\mathrm{T}$ to dihydrotestosterone (DHT). ${ }^{99}$ A systematic review and meta-analysis by Amiri et al showed that COCs could effectively improve the biochemical and clinical parameters of HA in PCOS patients. All COCs studies showed a similar increase in SHBG levels and decreases in the Ferriman-Gallwey (FG) score, T, FT, A4, and DHEAS levels; however, products containing cyproterone acetate (CPA) may be the most effective treatment for hirsute PCOS patients. ${ }^{100}$ In addition, a clinical study by Morgante et al showed that dienogest (DNG) has an important stimulating effect on SHBG concentration, which is less potent than that of drospirenone (DRSP) but more potent than that of chlormadinone acetate (CMA). ${ }^{101}$

\section{Inositol}

Inositol (MI) is a naturally occurring compound that has been studied extensively in the past decade due to its insulinsensitizing effect. ${ }^{102}$ Accordingly, several clinical trials have been conducted to evaluate the efficacy of MI in treating metabolic and reproductive diseases in women with PCOS. ${ }^{103,104}$ A meta-analysis by Facchinetti et al showed no 
difference in the effects of MET and MI on short-term hormonal changes such as FINS, HOMA-IR, T, and SHBG levels in PCOS subjects. ${ }^{105}$ However, our previous meta-analysis revealed that for women with PCOS, MI supplementation shows advantages in increasing SHBG, ameliorating HA, and glucose and lipid metabolism compared with placebo, coenzyme Q10, vitamin E, vitamin D, and other nutritious foods. ${ }^{106}$ In addition, the superior tolerance to MI makes it suitable for the recovery of androgen and metabolic characteristics in women with PCOS. ${ }^{105}$

\section{Vitamin D}

Accumulating evidence indicates that vitamin D deficiency (VDD) may be a pathogenic factor in the pathogenesis of IR and the PCOS metabolic syndrome. Approximately $67-85 \%$ of PCOS women show VDD, and there is a correlation between low vitamin D levels and IR, hirsutism, HA, and obesity. ${ }^{107}$ In addition, VDD is positively correlated with some well-known PCOS comorbidities (including T2DM, IR, metabolic syndrome, and cardiovascular disease). ${ }^{108}$ Vitamin $\mathrm{D}$ is a fat-soluble steroid hormone that can regulate calcium, magnesium, and phosphate homeostasis to maintain bone health and plays a key role as an anti-proliferative and immunomodulatory mediator. ${ }^{109}$ Vitamin D has a physiological role in reproduction, regulating follicular development by affecting the anti-Müllerian hormone (AMH) signal, FSH sensitivity, and progesterone production in ovarian granulosa cells. ${ }^{110}$ Furthermore, vitamin D appears to be able to regulate glucose-insulin homeostasis by acting on the auto-specific vitamin D receptor (VDR) located in pancreatic $\beta$ cells and skeletal muscle. Moreover, it directly activates the transcription of human insulin receptor genes, thereby activating peroxidation enzyme proliferator activator receptor-D, thus stimulating insulin receptor expression and enhancing insulin-mediated glucose transport in vitro. ${ }^{111}$ VDD may cause a wide range of extra-skeletal effects, affecting glucose homeostasis, cardiovascular disease, cancer, autoimmune diseases, and psychological disorders. ${ }^{112}$

The basic principle of vitamin D supplementation for PCOS women is based on the roles of vitamin D in glucose metabolism, enhancing insulin synthesis and release, increasing insulin receptor expression, and inhibiting proinflammatory cytokines. ${ }^{113}$ The effect of vitamin D on PCOS metabolism and reproductive dysfunction may be mediated by the overall effect on IR. In terms of reproduction, IR stimulates the production of ovarian androgens through insulin and aggravates HA with a reduction in SHBG. ${ }^{114}$ In terms of metabolism, IR is associated with impaired glucose tolerance, T2DM, and cardiovascular disease. Therefore, vitamin D may play a key role in the development of all clinical features of PCOS patients. ${ }^{115}$ Vitamin D supplementation is beneficial to plasma vitamin D levels and glucose metabolism; ${ }^{16}$ however, several published systematic reviews and meta-analyses have shown that oral vitamin D supplementation has almost no overall effect on the metabolic status of PCOS patients. ${ }^{106,117,118}$ A systematic review by Guo et al showed that oral vitamin D supplementation could reduce IR and hyperlipidemia but cannot reduce the androgen profile or inflammation markers in PCOS women with VDD. ${ }^{119}$ However, a meta-analysis by Azadi-Yazdi et al confirmed that vitamin D supplementation might significantly affect serum $\mathrm{T}$ but is not effective in improving other androgen profile markers. ${ }^{120}$ In addition, Jamilian et al demonstrated that compared with low-dose (1000 IU) and placebo groups, high-dose vitamin D (4000 IU) supplements had a significant beneficial effect on T, SHBG, and FAI. ${ }^{121}$ These beneficial effects of vitamin D on the clinical characteristics of PCOS may have multiple potential mechanisms. Further double-blind, placebo-controlled clinical trials are needed to explore the complex role of vitamin D in different pathways of this metabolic disorder.

\section{Probiotics, Prebiotics, and Synbiotics}

Prebiotics are difficult to digest and non-fermentable compounds that can enhance host health by reducing the binding and activity of harmful bacteria and increasing beneficial intestinal bacteria. Prebiotics can improve host health by increasing bifidobacteria, inhibiting pathogen growth and rotavirus activity, regulating the immune system, stimulating intestinal microporous bacteria activity, treating diarrhea and irritable bowel syndrome, preventing intestinal inflammation and cancer, etc. In terms of health, prebiotics interfere with lipid metabolism and increase $\mathrm{Fe}, \mathrm{Mg}, \mathrm{Ca}$, and $\mathrm{Zn}$ absorption by lowering intestinal $\mathrm{pH} .{ }^{122}$ Examples of prebiotics include inulin, resistant dextrin, oligofructose, oligofructose, galacto-oligosaccharide, and lactulose. ${ }^{122}$

Probiotics are non-pathological live microorganisms whose moderate consumption can positively affect the host by balancing the intestinal microbes. Lactic acid-producing bacteria, especially lactobacilli and bifidobacteria, are usually 
part of the gastrointestinal ecosystem, primarily located in the distal intestine and colon. Probiotics can effectively treat lactose intolerance and inflammatory bowel diseases, prevent autoimmune diseases, stimulate the immune system, possibly reduce cholesterol through bile acid uncoupling, regulate patient weight and blood lipids, reduce blood pressure, and prevent and treat infections. ${ }^{123}$

The term synbiotics refers to products that include probiotics and prebiotics, such as products containing fructooligosaccharides and bifidobacteria. Synbiotics improve host health by enhancing the survival rate of probiotics and implanting beneficial gut microbes. ${ }^{124}$ Therefore, it seems appropriate to use probiotics, prebiotics, and synbiotic supplements to treat PCOS, as they are effective and have few side effects. For example, Maryam et al found that PCOS women supplemented with probiotics for 12 weeks benefited in terms of T, SHBG, and F-G scores ${ }^{125}$ while Nasri et al found that PCOS women supplemented with synbiotics for 12 weeks benefited in terms of SHBG and F-G scores. ${ }^{126}$ In addition, a meta-analysis by Shamasbi et al showed that when synbiotics and probiotics were used in women with PCOS, SHBG was significantly increased, while FAI was significantly reduced. ${ }^{127}$ However, due to the limited number of studies on women with PCOS, more clinical studies are needed to determine the appropriate dosage, duration, and type of supplements.

\section{Conclusions}

Obesity, HA, IR, hyperinsulinemia, and hyperlipidemia are risk factors for PCOS. Low serum SHBG is associated with the complications and long-term prognosis of PCOS which plays an important role in its pathogenesis. Furthermore, PCOS is also related to genetic factors, and genetic SHBG polymorphisms can also affect the pathogenesis of PCOS. In addition, medications such as MET, GLP-1RAs, TZDs, and COCs as well as nutrient supplements such as MI, vitamin D, and synbiotics can regulate SHBG levels to ameliorate complications and improve the prognosis of PCOS. This review discusses the relationship between SHBG and PCOS, related molecular and genetic mechanisms, and related treatment methods. Despite this, there are still several issues that have not been resolved. In the future, more research is needed to explore the relationship between SHBG and PCOS, evaluate the effects of different interventions on SHBG levels and their therapeutic effects on PCOS.

\section{Acknowledgments}

This work was supported by the National Natural Science Foundation of China (grant no. 81570765).

\section{Disclosure}

The authors report no conflicts of interest in this work.

\section{References}

1. Wolf WM, Wattick RA, Kinkade ON, Olfert MD. Geographical prevalence of polycystic ovary syndrome as determined by region and race/ ethnicity. Int J Environ Res Public Health. 2018;15(11):2589. doi:10.3390/ijerph15112589

2. Rotterdam ESHRE/ASRM-Sponsored PCOS consensus workshop group. Revised 2003 consensus on diagnostic criteria and long-term health risks related to polycystic ovary syndrome (PCOS). Hum Reprod. 2004;19(1):41-47. doi:10.1093/humrep/deh098

3. Yilmaz M, Isaoglu U, Delibas IB, Kadanali S. Anthropometric, clinical and laboratory comparison of four phenotypes of polycystic ovary syndrome based on Rotterdam criteria. J Obstet Gynaecol Res. 2011;37(8):1020-1026. doi:10.1111/j.1447-0756.2010.01478.x

4. Costello MF, Misso ML, Balen A, et al. Evidence summaries and recommendations from the international evidence-based guideline for the assessment and management of polycystic ovary syndrome: assessment and treatment of infertility. Hum Reprod Open. 2019;2019(1):hoy021. doi:10.1093/hropen/hoy021

5. Zhu JL, Chen Z, Feng WJ, Long SL, Mo ZC. Sex hormone-binding globulin and polycystic ovary syndrome. Clin Chim Acta. 2019;499:142-148. doi:10.1016/j.cca.2019.09.010

6. Dapas M, Lin FTJ, Nadkarni GN, et al. Distinct subtypes of polycystic ovary syndrome with novel genetic associations: an unsupervised, phenotypic clustering analysis. PLoS Med. 2020;17(6):e1003132. doi:10.1371/journal.pmed.1003132

7. Hammond GL, Wu TS, Simard M. Evolving utility of sex hormone-binding globulin measurements in clinical medicine. Curr Opin Endocrinol Diabetes Obes. 2012;19(3):183-189. doi:10.1097/MED.0b013e328353732f

8. Saddick SY. Identifying genes associated with the development of human polycystic ovary syndrome. Saudi J Biol Sci. 2020;27(5):1271-1279. doi:10.1016/j.sjbs.2020.01.012

9. Lim SS, Kakoly NS, Tan JWJ, et al. Metabolic syndrome in polycystic ovary syndrome: a systematic review, meta-analysis and meta-regression. Obes Rev. 2019;20(2):339-352. doi:10.1111/obr.12762

10. Anderson AD, Solorzano CM, McCartney CR. Childhood obesity and its impact on the development of adolescent PCOS. Semin Reprod Med. 2014;32(3):202-213. doi:10.1055/s-0034-1371092 
11. Qu X, Donnelly R. Sex Hormone-Binding Globulin (SHBG) as an early biomarker and therapeutic target in polycystic ovary syndrome. Int J Mol Sci. 2020;21(21):8191. doi:10.3390/ijms21218191

12. Moran LJ, Hutchison SK, Norman RJ, Teede HJ. Lifestyle changes in women with polycystic ovary syndrome. Cochrane Database Syst Rev. 2011;2:CD007506.

13. Teede HJ, Misso ML, Costello MF, et al. Recommendations from the international evidence-based guideline for the assessment and management of polycystic ovary syndrome. Hum Reprod. 2018;33(9):1602-1618. doi:10.1093/humrep/dey256

14. Hammond GL, Bocchinfuso WP. Sex hormone-binding globulin: gene organization and structure/function analyses. Horm Res. 1996;45(35):197-201. doi:10.1159/000184787

15. Goldman AL, Bhasin S, Wu FCW, Krishna M, Matsumoto AM, Jasuja R. A reappraisal of testosterone's binding in circulation: physiological and clinical implications. Endocr Rev. 2017;38(4):302-324. doi:10.1210/er.2017-00025

16. Karakas SE. New biomarkers for diagnosis and management of polycystic ovary syndrome. Clin Chim Acta. 2017;471:248-253. doi:10.1016/j. cca.2017.06.009

17. Ruth KS, Day FR, Tyrrell J, et al. Using human genetics to understand the disease impacts of testosterone in men and women. Nat Med. 2020;26(2):252-258. doi:10.1038/s41591-020-0751-5

18. Saez-Lopez C, Brianso-Llort L, Torres-Torronteras J, Simó R, Hammond GL, Selva DM. Resveratrol increases hepatic SHBG expression through human constitutive androstane receptor: a new contribution to the French Paradox. Sci Rep. 2017;7(1):12284. doi:10.1038/s41598-01712509-x

19. Selva DM, Hammond GL. Thyroid hormones act indirectly to increase sex hormone-binding globulin production by liver via hepatocyte nuclear factor-4alpha. J Mol Endocrinol. 2009;43(1):19-27. doi:10.1677/JME-09-0025

20. Simó R, Saez-Lopez C, Lecube A, Hernandez C, Fort JM, Selva DM. Adiponectin upregulates SHBG production: molecular mechanisms and potential implications. Endocrinology. 2014;155(8):2820-2830. doi:10.1210/en.2014-1072

21. Simó R, Barbosa-Desongles A, Lecube A, Hernandez C, Selva DM. Potential role of tumor necrosis factor- $\alpha$ in downregulating sex hormonebinding globulin. Diabetes. 2012;61(2):372-382. doi:10.2337/db11-0727

22. Simó R, Barbosa-Desongles A, Hernandez C, Selva DM. IL1 $\beta$ down-regulation of sex hormone-binding globulin production by decreasing HNF-4 $\alpha$ via MEK-1/2 and JNK MAPK pathways. Mol Endocrinol. 2012;26(11):1917-1927. doi:10.1210/me.2012-1152

23. Feng C, Jin Z, Sun L, et al. Endogenous SHBG levels correlate with that of glucose transporters in insulin resistance model cells. Mol Biol Rep. 2019;46(5):4953-4965. doi:10.1007/s11033-019-04946-w

24. Selva DM, Hogeveen KN, Innis SM, Hammond GL. Monosaccharide-induced lipogenesis regulates the human hepatic sex hormone-binding globulin gene. J Clin Invest. 2007;117(12):3979-3987. doi:10.1172/JCI32249

25. Saez-Lopez C, Barbosa-Desongles A, Hernandez C, et al. Sex hormone-binding globulin reduction in metabolic disorders may play a role in NAFLD development. Endocrinology. 2017;158(3):545-559. doi:10.1210/en.2016-1668

26. Xie X, Liao H, Dang H, et al. Down-regulation of hepatic HNF4alpha gene expression during hyperinsulinemia via SREBPs. Mol Endocrinol. 2009;23(4):434-443. doi:10.1210/me.2007-0531

27. Lim SS, Norman RJ, Davies MJ, Moran LJ. The effect of obesity on polycystic ovary syndrome: a systematic review and meta-analysis. Obes Rev. 2013;14(2):95-109. doi:10.1111/j.1467-789X.2012.01053.x

28. Pugeat M, Nader N, Hogeveen K, Raverot G, Déchaud H, Grenot C. Sex hormone-binding globulin gene expression in the liver: drugs and the metabolic syndrome. Mol Cell Endocrinol. 2010;316(1):53-59. doi:10.1016/j.mce.2009.09.020

29. Nokoff N, Thurston J, Hilkin A, et al. Sex differences in effects of obesity on reproductive hormones and glucose metabolism in early puberty. J Clin Endocrinol Metab. 2019;104(10):4390-4397. doi:10.1210/jc.2018-02747

30. Cassar S, Misso ML, Hopkins WG, Shaw CS, Teede HJ, Stepto NK. Insulin resistance in polycystic ovary syndrome: a systematic review and meta-analysis of euglycaemic-hyperinsulinaemic clamp studies. Hum Reprod. 2016;31(11):2619-2631. doi:10.1093/humrep/dew243

31. Gholinezhad M, Gholsorkhtabaramiri M, Esmaeilzadeh S, Ghanbarpour A. Insulin resistance and adverse metabolic profile in overweight/ obese and normal weight of young women with polycystic ovary syndrome. Caspian J Intern Med. 2018;9(3):260-267. doi:10.22088/ cjim.9.3.260

32. Dadachanji R, Shaikh N, Mukherjee S. Genetic variants associated with hyperandrogenemia in PCOS pathophysiology. Genet Res Int. 2018;2018:7624932. doi:10.1155/2018/7624932

33. Jonard S, Dewailly D. The follicular excess in polycystic ovaries, due to intra-ovarian hyperandrogenism, may be the main culprit for the follicular arrest. Hum Reprod Update. 2004;10(2):107-117. doi:10.1093/humupd/dmh010

34. Shorakae S, Ranasinha S, Abell S, et al. Inter-related effects of insulin resistance, hyperandrogenism, sympathetic dysfunction and chronic inflammation in PCOS. Clin Endocrinol (Oxf). 2018;89(5):628-633. doi:10.1111/cen.13808

35. Li L, Feng Q, Ye M, He Y, Yao A, Shi K. Metabolic effect of obesity on polycystic ovary syndrome in adolescents: a meta-analysis. $J$ Obstet Gynaecol. 2017;37(8):1036-1047. doi:10.1080/01443615.2017.1318840

36. Hammond GL. Diverse roles for sex hormone-binding globulin in reproduction. Biol Reprod. 2011;85(3):431-441. doi:10.1095/ biolreprod.111.092593

37. Simó R, Sáez-López C, Barbosa-Desongles A, Hernández C, Selva DM. Novel insights in SHBG regulation and clinical implications. Trends Endocrinol Metab. 2015;26(7):376-383. doi:10.1016/j.tem.2015.05.001

38. Handelsman DJ, Sikaris K, Ly LP. Estimating age-specific trends in circulating testosterone and sex hormone-binding globulin in males and females across the lifespan. Ann Clin Biochem. 2016;53(Pt 3):377-384. doi:10.1177/0004563215610589

39. Shahebrahimi K, Jalilian N, Bazgir N, Rezaei M. Comparison clinical and metabolic effects of metformin and pioglitazone in polycystic ovary syndrome. Indian J Endocrinol Metab. 2016;20(6):805-809. doi:10.4103/2230-8210.192925

40. Petersen MC, Shulman GI. Mechanisms of insulin action and insulin resistance. Physiol Rev. 2018;98(4):2133-2223. doi:10.1152/ physrev.00063.2017

41. Wang Y, Viscarra J, Kim SJ, Sul HS. Transcriptional regulation of hepatic lipogenesis. Nat Rev Mol Cell Biol. 2015;16(11):678-689. doi:10.1038/nrm4074

42. Tawfeek MA, Alfadhli EM, Alayoubi AM, El-Beshbishy HA, Habib FA. Sex hormone binding globulin as a valuable biochemical marker in predicting gestational diabetes mellitus. BMC Womens Health. 2017;17(1):18. doi:10.1186/s12905-017-0373-3 
43. Le S, Xu L, Schumann M, et al. Does sex hormone-binding globulin cause insulin resistance during pubertal growth? Endocr Connect. 2019;8 (5):510-517. doi:10.1530/EC-19-0044

44. Lin XF, Wu RR, Du J, et al. Exploring the significance of sex hormone-binding globulin examination in the treament of women with polycystic ovarian syndrome (PCOS). Clin Exp Obstet Gynecol. 2015;42(3):315-320.

45. Saez-Lopez C, Villena JA, Simó R, Selva DM. Sex hormone-binding globulin overexpression protects against high-fat diet-induced obesity in transgenic male mice. $J$ Nutr Biochem. 2020;85:108480. doi:10.1016/j.jnutbio.2020.108480

46. Sáez-López C, Salcedo-Allende MT, Hernandez C, Simó-Servat O, Simó R, Selva DM. Sex hormone-binding globulin expression correlates with acetyl-coenzyme A carboxylase and triglyceride content in human liver. J Clin Endocrinol Metab. 2019;104(5):1500-1507. doi:10.1210/ jc. $2018-00740$

47. Selva DM, Hammond GL. Peroxisome-proliferator receptor gamma represses hepatic sex hormone-binding globulin expression. Endocrinology. 2009;150(5):2183-2189. doi:10.1210/en.2008-1289

48. Feng C, Jin Z, Chi X, et al. SHBG expression is correlated with PI3K/AKT pathway activity in a cellular model of human insulin resistance. Gynecol Endocrinol. 2018;34(7):567-573. doi:10.1080/09513590.2017.1411474

49. Chang RJ. The reproductive phenotype in polycystic ovary syndrome. Nat Clin Pract Endocrinol Metab. 2007;3(10):688-695. doi:10.1038/ ncpendmet0637

50. Cho LW, Jayagopal V, Kilpatrick ES, Holding S, Atkin SL. The LH/FSH ratio has little use in diagnosing polycystic ovarian syndrome. Ann Clin Biochem. 2006;43(Pt 3):217-219. doi:10.1258/000456306776865188

51. Huang M, Liu J, Lin X, et al. Relationship between dietary carbohydrates intake and circulating sex hormone-binding globulin levels in postmenopausal women. J Diabetes. 2018;10(6):467-477. doi:10.1111/1753-0407.12550

52. Ong M, Cheng J, Jin X, et al. Paeoniflorin extract reverses dexamethasone-induced testosterone over-secretion through downregulation of cytochrome P450 17A1 expression in primary murine theca cells. J Ethnopharmacol. 2019;229:97-103. doi:10.1016/j.jep.2018.09.006

53. Yin Y, Zhang Y, Zhang H, Jiang D, Guo G. [Clinical therapeutic effects of acupuncture combined with Chinese herbal medicine on infertility of polycystic ovary syndrome in the patients with ovulation induction with letrozole]. Zhongguo Zhen Jiu. 2018;38(1):27-32. Chinese. doi:10.13703/j.0255-2930.2018.01.006

54. Longo M, Zatterale F, Naderi J, et al. Adipose tissue dysfunction as determinant of obesity-associated metabolic complications. Int J Mol Sci. 2019;20(9):2358. doi:10.3390/ijms20092358

55. Cinar N, Gurlek A. Association between novel adipocytokines adiponectin, vaspin, visfatin, and thyroid: an experimental and clinical update. Endocr Connect. 2013;2(4):R30-R38. doi:10.1530/EC-13-0061

56. Liu CC, Huang SP, Cheng KH, et al. Lower SHBG level is associated with higher leptin and lower adiponectin levels as well as metabolic syndrome, independent of testosterone. Sci Rep. 2017;7(1):2727. doi:10.1038/s41598-017-03078-0

57. Simó R, Barbosa-Desongles A, Sáez-Lopez C, Lecube A, Hernandez C, Selva DM. Molecular mechanism of TNF $\alpha$-induced down-regulation of SHBG expression. Mol Endocrinol. 2012;26(3):438-446. doi:10.1210/me.2011-1321

58. Oróstica L, Astorga I, Plaza-Parrochia F, et al. Proinflammatory environment and role of TNF- $\alpha$ in endometrial function of obese women having polycystic ovarian syndrome. Int J Obes (Lond). 2016;40(11):1715-1722. doi:10.1038/ijo.2016.154

59. Yamazaki H, Kushiyama A, Sakoda H, et al. Protective effect of sex hormone-binding globulin against metabolic syndrome: in vitro evidence showing anti-inflammatory and lipolytic effects on adipocytes and macrophages. Mediators Inflamm. 2018;2018:3062319. doi:10.1155/2018/ 3062319

60. Hammond GL. Plasma steroid-binding proteins: primary gatekeepers of steroid hormone action. J Endocrinol. 2016;230(1):R13-R25. doi:10.1530/JOE-16-0070

61. Ferk P, Teran N, Gersak K. The (TAAAA)n microsatellite polymorphism in the SHBG gene influences serum SHBG levels in women with polycystic ovary syndrome. Hum Reprod. 2007;22(4):1031-1036. doi:10.1093/humrep/del457

62. Fan W, Li S, Chen Q, Huang Z. Association between the (TAAAA)n SHBG polymorphism and PCOS: a systematic review and meta-analysis. Gynecol Endocrinol. 2013;29(7):645-650. doi:10.3109/09513590.2013.797394

63. Moran LJ, Teede HJ, Noakes M, Clifton PM, Norman RJ, Wittert GA. Sex hormone binding globulin, but not testosterone, is associated with the metabolic syndrome in overweight and obese women with polycystic ovary syndrome. J Endocrinol Invest. 2013;36(11):1004-1010. doi: $10.3275 / 9023$

64. Martínez-García MÁ, Gambineri A, Alpañés M, Sanchón R, Pasquali R, Escobar-Morreale HF. Common variants in the sex hormone-binding globulin gene (SHBG) and polycystic ovary syndrome (PCOS) in Mediterranean women. Hum Reprod. 2012;27(12):3569-3576. doi:10.1093/ humrep/des 335

65. Xita N, Georgiou I, Lazaros L, Psofaki V, Kolios G, Tsatsoulis A. The synergistic effect of sex hormone-binding globulin and aromatase genes on polycystic ovary syndrome phenotype. Eur J Endocrinol. 2008;158(6):861-865. doi:10.1530/EJE-07-0905

66. Cousin P, Calemard-Michel L, Lejeune H, et al. Influence of SHBG gene pentanucleotide TAAAA repeat and D327N polymorphism on serum sex hormone-binding globulin concentration in hirsute women. J Clin Endocrinol Metab. 2004;89(2):917-924. doi:10.1210/jc.2002021553

67. Hacıhanefioğlu B, Aybey B, Hakan Özön Y, Berkil H, Karşıdağ K. Association of anthropometric, androgenic and insulin-related features with polymorphisms in exon 8 of SHBG gene in women with polycystic ovary syndrome. Gynecol Endocrinol. 2013;29(4):361-364. doi:10.3109/ 09513590.2012.743006

68. Wickham EP 3rd, Ewens KG, Legro RS, Dunaif A, Nestler JE, Strauss JF 3rd. Polymorphisms in the SHBG gene influence serum SHBG levels in women with polycystic ovary syndrome. J Clin Endocrinol Metab. 2011;96(4):E719-E727. doi:10.1210/jc.2010-1842

69. Abu-Hijleh TM, Gammoh E, Al-Busaidi AS, et al. Common variants in the Sex Hormone-Binding Globulin (SHBG) gene influence SHBG levels in women with polycystic ovary syndrome. Ann Nutr Metab. 2016;68(1):66-74. doi:10.1159/000441570

70. Lass N, Kleber M, Winkel K, Wunsch R, Reinehr T. Effect of lifestyle intervention on features of polycystic ovarian syndrome, metabolic syndrome, and intima-media thickness in obese adolescent girls. J Clin Endocrinol Metab. 2011;96(11):3533-3540. doi:10.1210/jc.20111609 
71. Hoeger K, Davidson K, Kochman L, Cherry T, Kopin L, Guzick DS. The impact of metformin, oral contraceptives, and lifestyle modification on polycystic ovary syndrome in obese adolescent women in two randomized, placebo-controlled clinical trials. J Clin Endocrinol Metab. 2008;93(11):4299-4306. doi:10.1210/jc.2008-0461

72. Haqq L, McFarlane J, Dieberg G, Smart N. Effect of lifestyle intervention on the reproductive endocrine profile in women with polycystic ovarian syndrome: a systematic review and meta-analysis. Endocr Connect. 2014;3(1):36-46. doi:10.1530/EC-14-0010

73. Lim AJ, Huang Z, Chua SE, Kramer MS, Yong EL. Sleep duration, exercise, shift work and polycystic ovarian syndrome-related outcomes in a healthy population: a cross-sectional study. PLoS One. 2016;11(11):e0167048. doi:10.1371/journal.pone.0167048

74. Bennett WL, Aschmann HE, Puhan MA, et al. A benefit-harm analysis of adding basal insulin vs. sulfonylurea to metformin to manage type II diabetes mellitus in people with multiple chronic conditions. J Clin Epidemiol. 2019;113:92-100. doi:10.1016/j.jclinepi.2019.03.014

75. Cirillo F, Catellani C, Lazzeroni P, et al. MiRNAs regulating insulin sensitivity are dysregulated in Polycystic Ovary Syndrome (PCOS) ovaries and are associated with markers of inflammation and insulin sensitivity. Front Endocrinol (Lausanne). 2019;10:879. doi:10.3389/ fendo.2019.00879

76. Bargiota A, Diamanti-Kandarakis E. The effects of old, new and emerging medicines on metabolic aberrations in PCOS. Ther Adv Endocrinol Metab. 2012;3(1):27-47. doi:10.1177/2042018812437355

77. Heidari B, Lerman A, Lalia AZ, Lerman LO, Chang AY. Effect of metformin on microvascular endothelial function in polycystic ovary syndrome. Mayo Clin Proc. 2019;94(12):2455-2466. doi:10.1016/j.mayocp.2019.06.015

78. Guan $\mathrm{Y}$, Wang $\mathrm{D}, \mathrm{Bu} \mathrm{H}$, Zhao T, Wang $\mathrm{H}$. The effect of metformin on polycystic ovary syndrome in overweight women: a systematic review and meta-analysis of randomized controlled trials. Int J Endocrinol. 2020;2020:5150684. doi:10.1155/2020/5150684

79. Fulghesu AM, Romualdi D, Di Florio C, et al. Is there a dose-response relationship of metformin treatment in patients with polycystic ovary syndrome? Results from a multicentric study. Hum Reprod. 2012;27(10):3057-3066. doi:10.1093/humrep/des262

80. Tzotzas T, Karras SN, Katsiki N. Glucagon-like peptide-1 (GLP-1) receptor agonists in the treatment of obese women with polycystic ovary syndrome. Curr Vasc Pharmacol. 2017;15(3):218-229. doi:10.2174/1570161114666161221115324

81. Papaetis GS. Incretin-based therapies in prediabetes: current evidence and future perspectives. World J Diabetes. 2014;5(6):817-834. doi:10.4239/wjd.v5.i6.817

82. Yabe D, Seino Y, Seino Y. Incretin concept revised: the origin of the insulinotropic function of glucagon-like peptide-1 - the gut, the islets or both? J Diabetes Investig. 2018;9(1):21-24. doi:10.1111/jdi.12718

83. Ferjan S, Jensterle M, Oblak T, et al. An impaired glucagon-like peptide-1 response is associated with prediabetes in polycystic ovary syndrome with obesity. $J$ Int Med Res. 2019;47(10):4691-4700. doi:10.1177/0300060519865351

84. Abdalla MA, Deshmukh H, Atkin S, Sathyapalan T. The potential role of incretin-based therapies for polycystic ovary syndrome: a narrative review of the current evidence. Ther Adv Endocrinol Metab. 2021;12:2042018821989238. doi:10.1177/2042018821989238

85. Abdalla MA, Deshmukh H, Atkin S, Sathyapalan T. A review of therapeutic options for managing the metabolic aspects of polycystic ovary syndrome. Ther Adv Endocrinol Metab. 2020;11:2042018820938305. doi:10.1177/2042018820938305

86. Heppner KM, Baquero AF, Bennett CM, et al. GLP-1R signaling directly activates arcuate nucleus kisspeptin action in brain slices but does not rescue luteinizing hormone inhibition in ovariectomized mice during negative energy balance. eNeuro. 2017;4(1):ENEURO.0198-16.2016. doi:10.1523/ENEURO.0198-16.2016

87. Outeiriño-Iglesias V, Romaní-Pérez M, González-Matías LC, Vigo E, Mallo F. GLP-1 increases preovulatory LH source and the number of mature follicles, as well as synchronizing the onset of puberty in female rats. Endocrinology. 2015;156(11):4226-4237. doi:10.1210/en.20141978

88. Nishiyama Y, Hasegawa T, Fujita S, et al. Incretins modulate progesterone biosynthesis by regulating bone morphogenetic protein activity in rat granulosa cells. J Steroid Biochem Mol Biol. 2018;178:82-88. doi:10.1016/j.jsbmb.2017.11.004

89. Frøssing S, Nylander M, Chabanova E, et al. Effect of liraglutide on ectopic fat in polycystic ovary syndrome: a randomized clinical trial Diabetes Obes Metab. 2018;20(1):215-218. doi:10.1111/dom.13053

90. Nylander M, Frøssing S, Clausen HV, Kistorp C, Faber J, Skouby SO. Effects of liraglutide on ovarian dysfunction in polycystic ovary syndrome: a randomized clinical trial. Reprod Biomed Online. 2017;35(1):121-127. doi:10.1016/j.rbmo.2017.03.023

91. Xing C, Li C, He B. Insulin sensitizers for improving the endocrine and metabolic profile in overweight women with PCOS. J Clin Endocrinol Metab. 2020;105(9):2950-2963. doi:10.1210/clinem/dgaa337

92. Wu LM, Wang YX, Zhan Y, et al. Dulaglutide, a long-acting GLP-1 receptor agonist, can improve hyperandrogenemia and ovarian function in DHEA-induced PCOS rats. Peptides. 2021;145:170624. doi:10.1016/j.peptides.2021.170624

93. Xing C, Lv B, Zhao H, Wang D, Li X, He B. Metformin and exenatide upregulate hepatocyte nuclear factor-4 $\alpha$, sex hormone binding globulin levels and improve hepatic triglyceride deposition in polycystic ovary syndrome with insulin resistance rats. J Steroid Biochem Mol Biol. 2021;214:105992. doi:10.1016/j.jsbmb.2021.105992

94. Froment P, Gizard F, Staels B, Dupont J, Monget P. Un rôle pour PPARgamma dans la reproduction? [A role of PPARgamma in reproduction?] Med Sci (Paris). 2005;21(5):507-511. doi:10.1051/medsci/2005215507

95. Anastasiou OE, Canbay A, Fuhrer D, Reger-Tan S. Metabolic and androgen profile in underweight women with polycystic ovary syndrome. Arch Gynecol Obstet. 2017;296(2):363-371. doi:10.1007/s00404-017-4422-9

96. Schoppee PD, Garmey JC, Veldhuis JD. Putative activation of the peroxisome proliferator-activated receptor gamma impairs androgen and enhances progesterone biosynthesis in primary cultures of porcine theca cells. Biol Reprod. 2002;66(1):190-198. doi:10.1095/ biolreprod66.1.190

97. Xu Y, Wu Y, Huang Q. Comparison of the effect between pioglitazone and metformin in treating patients with PCOS: a meta-analysis. Arch Gynecol Obstet. 2017;296(4):661-677. doi:10.1007/s00404-017-4480-z

98. Jin P, Xie Y. Treatment strategies for women with polycystic ovary syndrome. Gynecol Endocrinol. 2018;34(4):272-277. doi:10.1080/ 09513590.2017 .1395841

99. Vrbíková J, Cibula D. Combined oral contraceptives in the treatment of polycystic ovary syndrome. Hum Reprod Update. 2005;11(3):277-291. doi:10.1093/humupd/dmi005 
100. Amiri M, Kabir A, Nahidi F, Shekofteh M, Ramezani Tehrani F. Effects of combined oral contraceptives on the clinical and biochemical parameters of hyperandrogenism in patients with polycystic ovary syndrome: a systematic review and meta-analysis. Eur J Contracept Reprod Health Care. 2018;23(1):64-77. doi:10.1080/13625187.2018.1435779

101. Morgante G, Cappelli V, Troì L, De Leo V. Evaluation of different antiandrogenic progestins on clinical and biochemical variables in polycystic ovary syndrome. Eur J Contracept Reprod Health Care. 2020;25(3):176-181. doi:10.1080/13625187.2020.1736546

102. Croze ML, Soulage CO. Potential role and therapeutic interests of myo-inositol in metabolic diseases. Biochimie. $2013 ; 95(10): 1811-1827$. doi:10.1016/j.biochi.2013.05.011

103. Unfer V, Facchinetti F, Orrù B, Giordani B, Nestler J. Myo-inositol effects in women with PCOS: a meta-analysis of randomized controlled trials. Endocr Connect. 2017;6(8):647-658. doi:10.1530/EC-17-0243

104. Unfer V, Nestler JE, Kamenov ZA, Prapas N, Facchinetti F. Effects of Inositol(s) in women with PCOS: a systematic review of randomized controlled trials. Int J Endocrinol. 2016;2016:1849162. doi:10.1155/2016/1849162

105. Facchinetti F, Orrù B, Grandi G, Unfer V. Short-term effects of metformin and myo-inositol in women with polycystic ovarian syndrome (PCOS): a meta-analysis of randomized clinical trials. Gynecol Endocrinol. 2019;35(3):198-206. doi:10.1080/09513590.2018.1540578

106. Zhang J, Xing C, Zhao H, He B. The effectiveness of coenzyme Q10, vitamin E, inositols, and vitamin D in improving the endocrine and metabolic profiles in women with polycystic ovary syndrome: a network meta-analysis. Gynecol Endocrinol. 2021;1-9. doi:10.1080/ 09513590.2021 .2011198

107. Thomson RL, Spedding S, Buckley JD. Vitamin D in the aetiology and management of polycystic ovary syndrome. Clin Endocrinol (Oxf). 2012;77(3):343-350. doi:10.1111/j.1365-2265.2012.04434.x

108. Krul-Poel YH, Snackey C, Louwers Y, et al. The role of vitamin D in metabolic disturbances in polycystic ovary syndrome: a systematic review. Eur J Endocrinol. 2013;169(6):853-865. doi:10.1530/EJE-13-0617

109. Loughrill E, Wray D, Christides T, Zand N. Calcium to phosphorus ratio, essential elements and vitamin D content of infant foods in the UK: possible implications for bone health. Matern Child Nutr. 2017;13(3):e12368. doi:10.1111/mcn.12368

110. Irani M, Merhi Z. Role of vitamin D in ovarian physiology and its implication in reproduction: a systematic review. Fertil Steril. 2014;102 (2):460-468.e3. doi:10.1016/j.fertnstert.2014.04.046

111. Alvarez JA, Ashraf A. Role of vitamin d in insulin secretion and insulin sensitivity for glucose homeostasis. Int $J$ Endocrinol. 2010;2010:351385. doi:10.1155/2010/351385

112. Holick MF. The vitamin D deficiency pandemic: approaches for diagnosis, treatment and prevention. Rev Endocr Metab Disord. 2017;18 (2):153-165. doi:10.1007/s11154-017-9424-1

113. Angellotti E, D'Alessio D, Dawson-Hughes B, et al. Vitamin D supplementation in patients with type 2 diabetes: the vitamin D for established type 2 diabetes (DDM2) Study. J Endocr Soc. 2018;2(4):310-321. doi:10.1210/js.2018-00015

114. Plymate SR, Matej LA, Jones RE, Friedl KE. Inhibition of sex hormone-binding globulin production in the human hepatoma (Hep G2) cell line by insulin and prolactin. J Clin Endocrinol Metab. 1988;67(3):460-464. doi:10.1210/jcem-67-3-460

115. He C, Lin Z, Robb SW, Ezeamama AE. Serum vitamin D levels and polycystic ovary syndrome: a systematic review and meta-analysis. Nutrients. 2015;7(6):4555-4577. doi:10.3390/nu7064555

116. Menichini D, Facchinetti F. Effects of vitamin D supplementation in women with polycystic ovary syndrome: a review. Gynecol Endocrinol. 2020;36(1):1-5. doi:10.1080/09513590.2019.1625881

117. Fang F, Ni K, Cai Y, Shang J, Zhang X, Xiong C. Effect of vitamin D supplementation on polycystic ovary syndrome: a systematic review and meta-analysis of randomized controlled trials. Complement Ther Clin Pract. 2017;26:53-60. doi:10.1016/j.ctcp.2016.11.008

118. Łagowska K, Bajerska J, Jamka M. The role of vitamin D oral supplementation in insulin resistance in women with polycystic ovary syndrome: a systematic review and meta-analysis of randomized controlled trials. Nutrients. 2018;10(11):1637. doi:10.3390/nu10111637

119. Guo S, Tal R, Jiang H, Yuan T, Liu Y. Vitamin D supplementation ameliorates metabolic dysfunction in patients with PCOS: a systematic review of RCTs and insight into the underlying mechanism. Int J Endocrinol. 2020;2020:7850816. doi:10.1155/2020/7850816

120. Azadi-Yazdi M, Nadjarzadeh A, Khosravi-Boroujeni H, Salehi-Abargouei A. The effect of vitamin D supplementation on the androgenic profile in patients with polycystic ovary syndrome: a systematic review and meta-analysis of clinical trials. Horm Metab Res. $2017 ; 49(3): 174-179$. doi:10.1055/s-0043-103573

121. Jamilian M, Foroozanfard F, Rahmani E, Talebi M, Bahmani F, Asemi Z. Effect of two different doses of vitamin D supplementation on metabolic profiles of insulin-resistant patients with polycystic ovary syndrome. Nutrients. 2017;9(12):1280. doi:10.3390/nu9121280

122. Tsai YL, Lin TL, Chang CJ, et al. Probiotics, prebiotics and amelioration of diseases. J Biomed Sci. 2019;26(1):3. doi:10.1186/s12929-0180493-6

123. Indira M, Venkateswarulu TC, Abraham Peele K, Nazneen Bobby M, Krupanidhi S. Bioactive molecules of probiotic bacteria and their mechanism of action: a review. 3 Biotech. 2019;9(8):306. doi:10.1007/s13205-019-1841-2

124. Su P, Henriksson A, Mitchell H. Prebiotics enhance survival and prolong the retention period of specific probiotic inocula in an in vivo murine model. J Appl Microbiol. 2007;103(6):2392-2400. doi:10.1111/j.1365-2672.2007.03469.x

125. Karamali M, Eghbalpour S, Rajabi S, et al. Effects of probiotic supplementation on hormonal profiles, biomarkers of inflammation and oxidative stress in women with polycystic ovary syndrome: a randomized, double-blind, placebo-controlled trial. Arch Iran Med. 2018;21 (1): $1-7$.

126. Nasri K, Jamilian M, Rahmani E, Bahmani F, Tajabadi-Ebrahimi M, Asemi Z. The effects of synbiotic supplementation on hormonal status, biomarkers of inflammation and oxidative stress in subjects with polycystic ovary syndrome: a randomized, double-blind, placebo-controlled trial. BMC Endocr Disord. 2018;18(1):21. doi:10.1186/s12902-018-0248-0

127. Shamasbi SG, Ghanbari-Homayi S, Mirghafourvand M. The effect of probiotics, prebiotics, and synbiotics on hormonal and inflammatory indices in women with polycystic ovary syndrome: a systematic review and meta-analysis. Eur J Nutr. 2020;59(2):433-450. doi:10.1007/ s00394-019-02033-1 


\section{Publish your work in this journal}

The International Journal of Women's Health is an international, peer-reviewed open-access journal publishing original research, reports, editorials, reviews and commentaries on all aspects of women's healthcare including gynecology, obstetrics, and breast cancer. The manuscript management system is completely online and includes a very quick and fair peer-review system, which is all easy to use. Visit http://www. dovepress.com/testimonials.php to read real quotes from published authors.

Submit your manuscript here: https://www.dovepress.com/international-journal-of-womens-health-journal 